\title{
Historical Perception of Architecture and Cultural History Approach
}

\author{
Azin Ehteshami \\ Architecture and Planning Department, Isfahan University of Art, Isfahan, Iran \\ Email: azin.ehteshami68@gmail.com
}

How to cite this paper: Ehteshami, A. (2018). Historical Perception of Architecture and Cultural History Approach. Art and Design Review, 6, 76-95.

https://doi.org/10.4236/adr.2018.62008

Received: April 10, 2018

Accepted: May 28, 2018

Published: May 31, 2018

Copyright $\odot 2018$ by author and Scientific Research Publishing Inc. This work is licensed under the Creative Commons Attribution International License (CC BY 4.0).

http://creativecommons.org/licenses/by/4.0/

\begin{abstract}
The experts and specialists in the field of architecture have had different viewpoints and approaches in defining the concepts of "history" and "the history of architecture", all through the compiled history of architecture. Analysis of these viewpoints that are sometimes in contrast and sometimes similar to each other brings forward some questions in the minds of the addressees in the field of history of architecture regarding whether or not there is a comprehensive approach or definition about the history of architecture among the existing approaches! And, in case of a positive response, what are the approaches and what can be their specification? The present article, which is a qualitative study with descriptive-analytical approach, is organized with the aim and motivation to respond to the above questions, and it is done by collecting, interpretation, and analyzing the required data. This study has three main parts, the first of which deals with the redefinition of the concept of "history", the advantages and applications of the history. The second part analyzes the concept of "history of architecture" and searching in the most important viewpoints about that concept; according to these analyses, "the approach towards the cultural history" is introduced and determined as the most comprehensive approach in defining the history of architecture. The third part, which is indeed the complementary part of the descriptions in the second part, is allocated to the explanation of the components of architectural historical perception based on the cultural historical theory, clarifying that the cultural historical approach is the approach that represents "architectural historical perception" as the comprehensive perception of architecture and its history.
\end{abstract}

\section{Keywords}

History, Architectural History, Architectural Historical Perception, Cultural History 


\section{Introduction}

The present article, which is a qualitative study with descriptive-analytical approach, is organized with the aim and motivation to respond to the above questions, and it is done by collecting, interpretation, and analyzing the required data. This study has three main parts, the first of which deals with the redefinition of the concept of "history", the advantages and applications of the history. The second part analyzes the concept of "history of architecture" and searching in the most important viewpoints about that concept; according to these analyses, "the approach towards the cultural history" is introduced and determined as the most comprehensive approach in defining the history of architecture. The third part, which is indeed the complementary part of the descriptions in the second part, is allocated to the explanation of the components of architectural historical perception based on the cultural historical theory, clarifying that the cultural historical approach is the approach that represents "architectural historical perception" as the comprehensive perception of architecture and its history.

\section{A Look to History and Its Concept}

\subsection{The Nature of History}

What is history? What does it deal with? How does it proceed? And, what is it for? They are all, the questions that the experts have answered to some extent with regards to different aspects. Although there are extensive views in this respect, but common points can be found in them with a little contemplation, or at least, the important views can be found and determined.

As the beginning point of the subject, we herewith want to discuss about the field of history, its advantages, and its aims and final intentions, clarifying some of the concepts of this domain with regards to the objectives of this study. The nature of history has always been disagreed among the scholars, and this can indicate that the question about the state of history has existed among human beings from past centuries. The most important view among the past elites is perhaps the viewpoint by Aristotle. The extract of Aristotle's view about history (that is of course a pessimistic view) can be summarized into two different phrases, the first of which is that "history is not a science", and the other one indicates that "poetry is superior to history".

Since various sciences have a specific definition in Aristotelian school of thought (Aristotelianism), being placed in three different categories, namely theoretical (physics, mathematics, and metaphysics), practical (civic policies, household management, economics, etc.), and productive (lecture, poetry, and dialect), history has no contribution among them (Allsopp, 1992). According to him, science is an affair that expresses the nature or the reasons of some points and objects by stating the reasons and attributions. Accordingly, history cannot be considered as a science.

However, he expresses his viewpoint about history by a comparison; a comparison between poetry and history. Regardless of why he mainly compared 
poetry and history, his viewpoint about the nature of history is considerable. Aristotle considers history that deals with the affairs, in which according to him plausibility is not essential, to be inferior to poetry that deals with the general realities and probable affairs, and considers poetry to be more philosophical than history (Zarrinkoub, 2009: p. 28). According to Aristotle, a plausible and likely affair is one, in which there is no meaningless, incompatible, or ineffective thing that prevents from admitting it. However, he indicates that history lacks such a property, since it cannot be accepted or rejected spontaneously. Some points are hidden in his viewpoint, the first of which is that Aristotle has compared history with poetry and nothing else. This indicates that according to him, history in its own nature has relations with poetry, and literature as a whole. In fact, according to Aristotle, both history and poetry have roots in stories and fictions. The relation of history and fictions is such that the boundary between fictions and history has been damaged during the past centuries (and even today), and the history is sometimes written or narrated exactly as stories (Stanford, 2003). Aristotle's views led to pessimism of many scholars such as Descartes (Zarrinkoub, 2009: p. 28) and even Muslim elites (such as Avicenna and Farabi) towards history. However, this pessimism relative to history can be justified with regards to the type of literature and common stories in Aristotle's era (and even a long time after that). Reading the books such as "Herodotus History" and the mythical and irrational nature of the stories in that era is a clear reason to find out why an elite philosopher such as Aristotle has not considered history as a science. Thus, although Aristotle's viewpoint is the first recorded considerable view about history, but it can by no means be considered as the best and most perfect theory in that respect. We can see later that the viewpoints of the scholars after him and comparing them with each other will be a great help in more clarification of the subject.

Furthermore, despite looking at the pessimistic views of Aristotle towards history, the important point in his ideas is measuring the history and poetry with respect to philosophy. In fact, according to him, both of these affairs (i.e. history and poetry) have philosophical criterion, and he has considered the philosophical weight of poetry to be greater than that of history. This was perhaps a spark and starting point in the formation of the views of the recent scholars, who have considered history to be analogous with philosophy. For instance, the philosopher and critic of our era "Benedetto Croce (1866-1952)" considered history equivalent to philosophy, claiming that any philosopher is also a historian, and any historian is a philosopher. Croce considered history as the movable philosophy and admitted the point that history should be written by the philosophers (Ditto, p. 28).

Some other scholars, such as Michael Stanford, have considered history to be equivalent with philosophy in addition to being a science, regarding the natural similarities of history and philosophy so important to be contemplated. According to Stanford, since history deals with the affairs that are elapsed and are not comprehensive, objective experiences, and tangible, it is similar to philosophy, 
since the subject of philosophy is mainly dealing with abstractive and non-objective concepts (Bailer, 1999). On the other hand, philosophy and history have no specialized and technical language, solely allocated to them, similar to the experimental sciences [it would rather be said that they cannot have that sort of language]. Both of these affairs involve the daily spoken language as well as reasoning and rationalization (although rationalism and reasoning are different in philosophy and history). The other similarity of history and philosophy is that they both deal with all the human activities in all their aspects and dimensions, and their inclusion ranges are quite extensive and profound, although their views towards life are different.

However, according to some other scholars, history is a type of research and hence a kind of science. But, its type of science or research is not our subject of discussion. The important point is that according to them, history belongs to what is typically called "science"; i.e. the types of thought by which some questions arise and we try to answer them (Collingwood, "The general concept of history", 2006: p. 16). However, defining the science here is different to that of Aristotle. According to this view, the knowledge regarding our ignorance starts from a definite point and our past data are considered as tools, by the help of which we try to discover our considered subject. It is important to know that knowledge is not generally collecting what we know from the past and arrange them by this or that plan; it means sticking to what we do not know and trying to discover it (Ditto). In other words, what we already know has no value on its own, and it is only applied when it can help us in solving a problem of our era. Thus, according to its precise meaning, scientific knowledge is an affair that is naturally based on searching and discovering, with the aim to solve the problems in life and improve it in various domains, with the tools regarding the known points and past experiences. According to this definition, history is also a science, and similar to many other scientific fields, it is a science by which we try to arise various related questions and find the required answers to them, for our today's and tomorrow's world.

Irrespective of the different viewpoints of experts and scholars (Khoei, 2000), the important point that can be inferred through most of the views about history is the point that history is the basis to ask vital questions about life, and studying and researching in it is useful and even essential for finding the vital questions of life and human survival (Kostof, 1985).

\subsection{Subject of History}

Although history is naturally a science, but it can be found that this science is somewhat different with other sciences with regards to the subjects. Since history is involved with the "events" (all the past events) and "human activities" (all the human activities in the past), it has an extensive range as the extent of the world and with the depth for all the human actions (Zevi, 1997). Generally, despite the extraordinary range that can be regarded for the range of history, there are three main definitions about the science of history, as follows: 
1) All the past events and occasions are the subjects of the science of history

2) All the past events and occasions regarding "humans" are the subjects of the science of history

3) "Some" of the past human events and occasions are the subjects of the science of history

According to the $19^{\text {th }}$ century scholars and experts, such as Emerson ${ }^{1}$ and some others in the western world, all the past events, including human or natural events are the subjects of the science of history. In fact, if Emerson was asked what history was? He would answer that: "What is not history?" According to Emerson, history is the creator of all the phenomena in general and multilateral meanings, and any phenomenon, including solids, plants, and animals have their own history and life.

However, some others consider the human past as history, believing that any event cannot be considered as the history. According to them, "history started its fondness towards the past, when human beings appeared in it. The main attention of history is referring human experiences and actions. In other words, history focuses on human activities that are known even for a short while" (Walsh, p. 34). Collingwood is a scientist that his views are almost in conformity with that view. In the book "The general concept of history", he states that, "In answering the question regarding what the history discovers, I would say actionsthe human actions performed in the past."

However, according to some scholars, such as E.H.T. Carr, all the past events of humans cannot be considered as history. Only some events are included in historical occurrences or history. According to him, what the historians consider important is regarded as history. Anyhow, these experts are always exposed to the question about their main criterion in determining important historical events as compared to unimportant ones ${ }^{2}$.

Accordingly, more questions are arisen, many of which are challenging. But, any responses to them do not negate the validity of the fact that the range and limits of this science can be varied based on our questions regarding the historical science. In other words, out confrontation with history and our aim from the confrontation would determine the inclusions, and no definite limits can be considered for it.

\subsection{How Does History Proceed?}

History is involved with what has happened in the past. However, the past can never be present as a whole. Thus, our information about history is based on the points that are somehow recorded. The recorded points are the documents, by the interpretation of which history proceed. "Documents" is the plural form of "document", and a document is an existing object, by which a historian by thinking about it can respond to the questions about the past events (Colling-

${ }^{1}$ R.W. Emerson (1836)-American philosopher/writer, author of "The book of nature".

${ }^{2}$ For further readings, study "What is history?" by E.H. Carr. 
wood, 2006: p. 19). Obviously, the states and specifications of the documents bring various questions in mind. No matter what the specialists and ordinary people think, but the clear point is that the proceeding of history is mainly by "interpretation of the documents".

\subsection{What Is History for?}

The hardest question about history is probably is the mentioned question. The questions regarding the state of history and its advantages can be answered from the viewpoint of various scientific knowledge and different domains in life; e.g. the advantages of history in the fields of biology or medical sciences, or the effectiveness of history in social and cultural studies. But, there is a general and common point in all these aspects that other aims and objectives of studying the history are the subordinates of it, which can be considered as the ultimate aim of the history, and that is the "human being". In fact, the aim for studying the history in different domains is nothing but the developing the life of human beings, and history is exploiting better understanding of humans about themselves. It was mentioned that history means what human beings have done anywhere in the world, in the past. Thus, in fact, human beings in the history only indicate their actions in the past, and human knowledge means "recognizing that human being did in the past", and "reaching to what he can do at present". In this regard, Collingwood states that, "My answer to the question regarding "what the history is for" is that history is for self-knowledge. It is generally assumed that self-knowledge is important for humans; however, self-knowledge is not merely recognizing personal specifications and the other points that distinguish them from other people, and it is his nature in the position of a human being. Self-knowledge primarily indicates that you should know what being a human is. Secondly, it is for you to know "what type of human being you are", and thirdly, it is to show you "what type of human being that you are and nobody else is". Self-knowledge indicates what you can do. Since nobody knows what he can do, unless he tries, and also because the only clue about what a human being can do is what he has already done, the prominence of history is that it teaches us what the human beings have done and hence, what is meant by "human being"(Ditto, P. 18). Dr. Abdolhossein Zarrinkoub has had the similar view in the book "History in scale", stating that, "An advantage of history is undoubtedly helping the humans to recognize themselves, distinguish them from others, and find out their concealed motivations and secrets as they are and as they should be, by comparing themselves with others" (Zarrinkoub, 2009: p. 12).

The general advantages stated in studying of history are for all the addressees. However, no other groups among the addressees require exploitation from the advantages of history than the adolescents and children. Due to young age and little experience, they require to find and retrieve themselves in their time and place positions, and history is the most important source for them to achieve the required cognition. According to Dr. Zarrinkoub, "History has the advantage, 
especially for the young people, to lead them to their era, earlier than usual, to open the windows on them and allow them to identify the dominating factors in the world, and distinguish what is required to be preserved from the things and aspects that are rejected" (Ditto). On the other hand, history is an enjoyable science, or according to Beihaghi ${ }^{3}$, "The science of history is a pleasing science" (Ditto, P. 19), thus, it attracts the readers. We may think about whether "joy" can be regarded as an advantage! Zarrinkoub answers this question as, "In fact, there is no pleasure that is not benefitting from any advantage, even if that advantage includes withdrawals that may be distressing" (Ditto, p. 20).

The other advantage of history, due to familiarizing human beings with the activities of their ancestors, is being the source of inspiration and their motivation for creation and construction. "Niche confirms that history familiarizes humans with the activities in the past; activities develop creativity in humans and encourage them towards the past honorable traditions" (Ditto, p. 13).

However, as mentioned earlier, the whole attention and the result of the advantages include "human beings", "human life", and its improvement. According to what was stated, history in general and based on the experts' viewpoints is: 1) a science and research or activity for responding to the questions, 2) related to the past actions, 3) proceeding via exploitation, analysis, and interpretation of documents, and 4) for the self-knowledge of humans.

\section{A look to the Architectural History (Different Views from the Concept of the History of Architecture)}

\subsection{Historical Deduction}

In a general view, all the existing deductions from the history of architecture can be considered as a historical deduction, since no human action (in any way we look at it) is away from the time span. George Sullivan is among the scholars that compares architectural history with the history as a whole, stating that:

"Architectural history is similar to other histories, with the aim to perceive and interpret the past. What distinguishes the architectural history from other histories is the nature of the existing documents and the methods used for evaluating the documents. Similar to any other historical study, the first stage is collecting the data and realities. Then, for any identification of the information, they should be selected, organized, evaluated, interpreted, and finally make the required substitutions" (Gardner, 1986).

Bruce Allsopp, the British historian considered a serious duty and regarded it as "the recorded experimental tests".

Indicating the architecture as a phenomenon with objective and extensive existence and researching potentials is an important point that this historian emphasized (GoleijaniMoghadam, 2005). According to Allsopp and others with the same viewpoints, the instructive aspect of the architectural history and its appli-

${ }^{3}$ Beihaghi talks about "historical science". Thus, our ancestors, including him considered history as a science 
cations are the points, which are important. By paying attention to these views, we can realize that although such views seem extremely idealistic, but they are important since they make the addressees with many advantages of architecture. In such views, the duty of the history of architecture is as a scientific aspect that is indicated.

\subsection{Architectural Deductions}

The architectural deductions from the history of architecture can be mainly attributed to the architects of architectural historians. Perhaps it is the reason that according to them, the most important subject in the architectural history is indeed the creation of space and following the transformations. In fact, the architects and architectural historians have always been exploiting something beyond what the other historians are looking for, which has been "achieving the spatial values in different eras" (Ditto). Although the deduction of people about the concept of space in architecture is most probably not similar, but paying attention only to the subject of space is the fact that other historians have not properly considered. Some scholars have considered the apparent and morphological viewpoints towards the history of architecture as the architectural deductions in this domain. We have not herewith dealt with such views, and we have referred to them in the section "artistic and aesthetic deductions".

One of the scholars, who has considered the spatial knowledge and the state of its creation in different periods and places in his writings is Sigfried Giedion. In defining the history of architecture, he emphasizes on the value and application of space, as "the architectural expression as the heir of spatial concepts. Emphasis on space, as main architectural specification, represents its main distinctive aspect by equivalent historical inclinations with architecture, similar to different types of arts, and hence, any definition about architecture and the distinctive subordinates from that will be insufficient without that peculiar dimension" (Giedion, 1995).

In his famous book, called "Space, time, architecture", Giedion has considered the space quality and its properties as the basis of most of his comparisons and analyses for architecture in different times and places. Bruno Zevi is also another expert, who has paid special attention to the concept of space in the architectural history. He mainly considers the history of architecture as "the history of perceiving the building interior spaces", since that is the boundary to distinguish between architecture, sculpture, and structure. He considers other values along with the space, stating that, "The point that the interior space is the essence of architecture does not mean that the value of an architectural work terminates in its spatial value; each construction is defined by a set of values, namely economic, social, technical, functional, artistic, spatial, and decorating values" (Ditto). He believes in writing the history by considering all the values. Although its basis is considered to be "the space", but the space can be defined by the mentioned elements. 
In fact, by expressing such a point of view, Zevi et al. believe that although space is considered as the most important recognizing factor of architecture, as compared to the other phenomena, but the perception and more comprehensive and profound knowledge of the past architecture depends on the multilateral knowledge of all of its elements.

\subsection{Artistic or Aesthetic Deductions}

Due to its artistic nature and the visual and aesthetic aspects, in the books regarding history of art, architecture has always been placed along with painting and sculpture, allocating an important part of the studies in the history of art to itself. Since the history of architecture is derived from the history of art, many of the definitions that are true for the history of art are also true for the history of architecture. According to Helen Gardner:

"The history of art benefits from various methods and tools for getting closer to the reality of the artistic work. Distinction of the works based on the existing morphology, time, or the created eras-as the painting styles, or classification according to the theme, and symbols-are among the mentioned methods. The efficacy of these methods have always been criticized. In the history of art, an artistic work is an object and simultaneously a historical event. Due to its visibility and tangibility, an artistic work is somewhat "an emerging event, but the forgotten and diminished events being the parts of the history are not in such a situation" (Gardner, 1986).

According to some of the analysts, various approaches for the historical studies are in three categories, namely practical, historical, and aesthetic approaches (Khoei, 2000). Their definitions about these three approaches are as follows:

"The reasons for constructing a building and its relations with the social, economic, political, cultural, and religious situations are searched in the historical approach. The specifications as well as the visual and style properties are dealt in the aesthetic approach, and the ways to change the styles and the required reasons are clarified" (Ditto).

It is believed that the older historical writings about architecture have been inclined in the history of architecture to the two practical and aesthetic approaches. In fact, the historians used primarily to try to introduce the architecture in different eras and different regions by analyzing the forms and styles of the buildings.

"One of the first books that is written based on the mentioned style and it is still found in book markets after almost a century, which is known by different generations of architecture students, that is written by Banister Fletcher is the famous book "History of architecture" for the students, specialists, and interested people, with the comparative look towards architectural styles from different eras, which was first published in 1896 (Ditto). What Fletcher and his son implemented in this book is using the comparative anatomical and comparative biological technics in the history of architecture. Comparison of the buildings, especially for showing the similarities and differences, is a method that is still used 
by the critics as well as the historians. This technic is useful, when the compared buildings have common points with each other; for instance, comparing a mediaeval church with a Victorian church in the Gothic restoration period, or comparing a Roman exhibition center with a modern sports stadium are quite apparent in that respect. However, comparing the buildings such as Roman exhibition center and the Victorian church that have only a few common points with each other cannot show any peculiar thing. This method is also successful for teaching and instruction purposes" (Ditto).

However, as it was earlier mentioned, there are some definitions in the history of art that are also true for the history of architecture. One of these definitions is the Gardner's definition in her book "Art in the passage of time". She states that:

"The aim of the history of art is recognizing and evaluation of the art from any place and at any time, and by whoever created. The two terms of art and history cannot be so close in the field of culture" (Goleijani Moghadam, 2005).

Placing these two concepts in the cultural domain by Gardner owes to the Johann Joachim Winckelmann (Father of the history of art) theory, in his own famous book, called "The history of ancient art", in which the relation between art and culture was considered for the first time.

In fact, according to that idea, each architectural work is placed in a context, which is the culture of the work. The more complete and recent type of this view in the field of the history of art and architecture is the view regarding the cultural studies, which will be dealt by the end of the required analyses.

\subsection{Archeological Deductions}

Archeology and its achievements have always been among the most serious resources of recognizing art and especially the past architectures. Many of the historical buildings are appeared and identified due to archeological excavations, and the related objects with the architectural technics and productions in the past, which are discovered during the archeological explorations, have responded to many of our questions about the past architectures. Moreover, many of the historical chronicles or the related articles with the history of architecture in the past decades by the archeologists include the definitions that the archeologists (especially the past archeologists) have given about architecture. They are deficient and imperfect definitions about architecture and although they involve an aspect among different aspects of architecture, but they never provide a perfect view about it. Bruno Zevi, the architectural expert states his dissatisfaction about the above point, as follows:

"Despite the fact that the attention of archeologists towards the text linguistics is considered valuable, but editing the past texts of architecture by them have confronted somewhat cool and depressing similar to the archeology" (Zevi, 1997).

\subsection{Analogous Deductions}

The historians of the history of architecture have sometimes highlighted archi- 
tecture in an analogous and allegorical framework. Although this image may appear unrealistic and non-objective in the first glance, but since it has made a non-intermediate relation with the feelings of the addressees and places them in a represented world (the world imagined by the historian), it is quite attractive. History and historical narrations have specific relations with stories and tales, and perhaps it is the reason that analogy of the history of architecture to something different and narrating that in a fictional and allegorical framework seems attractive.

Bruce Allsopp has brought one example of analogous definitions of the history of architecture in the introduction of his book "A general history of architecture". He defines the history of architecture within a frame of an old garden, and illustrates the architectural history conditions during different centuries by expressing the history and ups and downs of the life in that garden. The fictional theme of this narration and similar stories absorbs the readers to the text from the beginning, conducting them to the end. Although such a view is not based on scientific and rational reasons and frameworks, but the humanistic and close to life aspects of it has always been considered by the historians and also the addressees.

"In his book $A$ history of architecture, Spiro Kostov assimilates the history of architecture to a large tour that is moving during the history, such as walking in public places and streets of different cities including Esfahan or London, walking in a continuous and indoor space of Islamic buildings, or in Pantheon spaces in Rome” (Goleijani Moghadam, 2005).

\subsection{Deductions and Cultural History Approach}

There is another approach towards the concept of the history of architecture, which is more recent, more general, and more comprehensive, as compared to other views, and that is the approach of the cultural history. Generality of this approach is due to its decency, on one hand, which is considered as the consequence and resultant of all the past approaches, and on the other hand, it owes to the profound attitude related to the subject of culture. Since architecture is a collective affair, born from the communities' culture and civilization, it is clear that its better knowledge cannot be provided unless from the cultural and historical knowledge of those communities. Culture is naturally a general, multilateral, and pervasive concept, and when we talk about it, we indeed talk about whatever is distinguishing a community from other communities, during the history. Hence, when we look at architecture with the approach of the cultural history and consider architecture a cultural affair deriving from culture, out viewing horizon will include all the affairs and elements that have formed the architecture of a land and have been effective on its transformations and changes. Culture is also a historical affair, which can include all the historical deductions from the concept of the history of architecture, and also involves all the architectural concerns of the historians towards the space and architecture, 
since space is also arisen from human mind and human being is also a creature transformed by the culture. On the other hand, all the aesthetic definitions referring to the architectural forms and shapes are placed within the range of cultural definition regarding the history of architecture, since forms and shapes in art indicate the cultures and beliefs of each community.

Where the archeology views deal with the study of life and the traditions of past people, they involve with the cultural history, and the metaphor and allegory views of history reveals the manifestation of the language and culture of a land, where it is dealt with telling stories and the architectural metaphorical narration. Thus, only considering the studies of the surface and the body of architecture irrespective of its forming basis is a mistake that historians with the cultural history views always mention about it.

Although the cultural history approach (to the history and the history of architecture) is a new approach, but it has confronted various changes and has added different views, in almost the two centuries of its life. Thus, for better understanding of it is necessary to introduce and analyze the viewpoints and recognize the history of cultural history in a more appropriate manner.

The history of the cultural history is divided into 4 different stages:

"The classical stage (from the late $19^{\text {th }}$ century); the stage of the art social history (from the 1930s); the stage of the public cultural history, and the historical morphology (since 1960s); and, the new cultural history stage (since 1989)."

"There is no definite line between these four stages, but there have been the effective factors at each era that distinguishes them from their proceeding or succeeding stages" (Ghayoumi \& Shahidi, 2013). A brief review of the emergence of the cultural history shows that the term "cultural history" was used by the end of the $18^{\text {th }}$ century in Germany, for the first time, and gradually became popular in other countries, such as Britain. The first book in that domain that was the reference book for a long time for the historians was the book "The civilization of the Renaissance in Italy" written by Jacob Burckhardt, the Swiss historian. He has tried in his book to illustrate a comprehensive image of the culture that caused the emergence of Renaissance in Europe, via analyzing the different aspects of the civil community in the $15^{\text {th }}$ and $16^{\text {th }}$ century Italy. This viewpoint that was affected from the spirit of age (Zeitgeist) theory by Hegel, was used for a while in Europe (Ditto).

"Few articles and books were written about the history of architecture in the cultural history accomplishment era that the book the civilization of the Renaissance in Italy written by Jacob Burckhardt was one of them. Various research papers from the first grade resources of Renaissance, written by the experts as well as the memory and event notes, brief notes and photos and drawings from the author are collected in that book. Other cultural architectural historians learned considering such resources and points from Burckhardt" (Ditto).

After this stage, the cultural history studies entered into a new era, which was simultaneous with the dominance of some schools of thoughts and newly 
emerged ideologies that we considered it as the stage of art sociology with the art social history.

The stage of art sociology in the cultural history, i.e. 1930s and 1940s, was simultaneous with the growth of Marxism and attention of researcher to the importance of social and economic matters as well as the position of the inferior people in the history. The well-known historian for the art and architecture in this respect is Ernest Gombrich. His most important book "The story of art" is placed among the works for the cultural history, due to the paid attention to the historical and social points of the art and architecture works and attempts for perceiving them by the people in that period. Gombrich has also discussed about the theories of cultural history. His long lecture, which was later published as a book "In search of cultural history" became the basis for transformations in the cultural history. That book is about the intellectual paradigm of the first generation historians of the cultural history, regarding each historical era that consists of a cultural integrated generality. According to Gombrich, such an idea is rejected, since any art movement or style is mainly originated by the people rather than time. Thus, a cultural historian should be more precise in identifying the past events, and if the origins of the styles and artistic styles are dealt with, he should also consider the effective styles and relations in the artists dealing with the related styles (Ditto). The principles of the new cultural history were gradually formed according to such points of views, and changes were imposed to the past viewpoints.

"The new looks and more extensive attention of the historians to the concept of culture caused the cultural history to enter into a new phase by the end of the $20^{\text {th }}$ century, which is called "the new cultural history". The new cultural history, which is the modification of the past cultural history, has two important specifications: First, paying attention to the less observed subjects such as analysis of mentalities, feelings, and inappropriate matters; and secondly, paying attention to the considered subjects in the related fields to the culture" (Ditto).

The specifications of the new cultural history and its special attentions have made considerable holistic and generalities to that point of view. According to the explanations and irrespective of the discrepancies between different interpretations from the history of architecture, it is clear that what makes the basis of important thoughts in the field of the history of architecture is indeed paying or not paying attention to human beings and their lives, i.e. the human culture; the affair that its existence or lack of it is in different thoughts, distinguishing and recognizing various schools of thought. However, the approach towards the cultural history has different specifications, the most important of which are as follows:

Firstly, this approach is an inter-disciplinary approach, and its difference with other approaches is in inclusion of the subjects and the diversity of them, rather than the required method. This interpretation of the history of architecture benefits from the achievements of all the other sciences in different fields of studies. The other feature of this approach that is derived from the previous feature is the 
intensity and diversity of the documents. In fact, every historical document can be a reference for studying the approach.

"Interpretation of the functions: Paying attention to the functions for finding the hidden beliefs and regulations and paying attention to the practices depending on the phenomena or emergence of the phenomena are among the many features of cultural history studies" (Ditto).

When the history of architecture is viewed according to the approach of the cultural history, all the social classes will have similar values, and all the cultural achievements are considered valuable. That is another feature of the approach. Accordingly, and based on the explanations, "the approach of cultural history" can be considered to be more comprehensive than the other approaches in the domain of the history of architecture. Thus, it is clear that our aim from the history of architecture in this article is indeed "the architectural cultural history", and hence, whatever is effective in formation of architecture in a culture will be in the range of related studies and can be utilized in this respect.

\section{Components of Culture (Architectural Historical-Cultural Cognition Components)}

"The requirement for architectural perception is to find out that architecture is a cultural affair, and hence, it is also a historical affair, since no culture is established instantaneously. All the rich, poor, prominent, or weak cultures in the world are established and developed during the history. Since the relation between architecture and culture is not a direct, non-intermediate, and apparent relation, the emerged elements or components of the culture cannot easily be separated and distinguished from the produced elements of architecture. The relation is similar to the relation of a person with his family and their effects on each other; as it cannot clearly be stated that which physical, temperamental, and mental characteristics of a child in a family is derived from which characteristics of his/her parents, but it can be determined that he/she is the child of that family from the personal characteristics of the child and the similarities with the parents and other members of his/her family" (Warburton, 2016).

The components that we shall deal with are the main cognitive components of culture, which are not only affecting the architecture, but also they are effecting all the cultural manifestations, interfering in formation of all the components. EslamiNadoushan believes that the development of ideologies of a tribe or a race include fixed and variable factors, which gradually turns it into a propensity. He refers to two important factors of geographical situation and the region that substantiate a third effective factor, which is history (Gharibpour \& Toutounch, 2016). Mehdi Hojjat believes that "culture is the multiplication of geography in history, although there is a third factor that is the beliefs and ideologies. The elements of time, place, and beliefs are the elements that form the demography of people. When these elements are beside each other, it shall be called "originality" (Ditto). He talks about identity in relation with the culture, believing that 
"the identity of each creature arises from three different elements: geography or the natural environment, where a human is created, the history that has occurred, and also his beliefs" (Ditto).

\subsection{Worldview and Beliefs}

It is not wrong, if we consider humans' worldview and beliefs as the most important establishing element of culture and cultural manifestations. As it can be noticed from its notion, the worldview determines the type of human look towards the world, forming all the actions and reactions of humans in the world. Thus, recognizing the worldview is the main way to recognize the culture and hence, the cultural manifestations including the architecture. According to Seyed Hossein Nasr, it is the most important component of culture: "Culture includes any result of the thought, making, or practicing the action that reflects the worldview dominating a community. However, the more specific concept of it is reflecting the spiritual aspects of the worldview on different dimensions of human life, while the more general concept of it involves the results, interactions, and daily activities of humans" (Nasr, 2005).

\subsubsection{Religions and Religious Instructions}

It is not an exaggeration, if we say that religion forms the main and the most important part of worldviews in everyone. Religion includes a collection of instructions and these instructions are always accompanied by enjoining to good and forbidding from evil, or encouragements and punishments in life. "Religions and religious instructions are among the factors that have direct and indirect effects on architecture. Religions and religious instructions are affect the style of life, traditions, and human instincts, in architects and even the architectural users, from one side, and the religious or ethical living spaces or other buildings, from the other side. Different types of buildings constructed from the beginning of human life and also all the building that have relations with different aspects of human life indicate the effects of religion on human life and architecture. Considering the religion and its instructions will be meaningful with respect to the coordination of body and religious ceremonies and also with regards to the structure and the dominating space on the design. Thus, to perceive the architecture of a land, the relation between the religion and religious instructions with architecture and their mutual effects on each other should be contemplated" (Ditto).

\subsubsection{Traditions, Ethics, and Behaviors}

One of the other important components of culture in each community is the traditions of the people in that community. These traditions can either have religious aspects or be derived from other traditions in a community. However, arisen from any element, the traditions and rituals of any nation are the inevitable parts of human life, and they can be effective in the formation of people's existence. In addition to directly affecting the architecture, rituals and other tradi- 
tions are also effective on the ideologies and lifestyles of humans, indirectly.

\subsubsection{Human Look to His Own Existence and the World}

How human beings consider their position in the world and where they can find themselves in it has a profound effect in his worldviews, having a prominent importance in determining his attitudes towards life. This is particularly so, because it determines the type of his interactions with the nature and his surrounding world. "For instance, one of the features in Iranian culture is to distinguish the spiritual and the material worlds. This intrinsic view and the innate relations between the appearance and the backend conscience and has been among the cultural characteristics of Iranians, having its most profound effects in their behaviors with each other, deducing the speeches and behaviors of others, as well as in expressing and creating the artistic works" (Ditto). Such a belief has also been effective on the Iranian views towards the nature. Both in the ancient eras and in the Islamic era, the Iranians considered the sky, earth, mountains, plains, deserts, and seas not only the various aspects of the natural world and required elements for human life, but they are also considered for the spiritual connections between the nature and human beings. Humans should learn thinking and interacting about the nature as the ethics and rituals that reflect greater realities. Otherwise, the nature is studied as a creature that can be manipulated and dominated, and therefore, it can never be perceived realistically" (Nasr, 2007).

\subsection{The Domain of Historical Transformations}

All the human activities are placed within the historical time span, since they require time, and they ought to be occurred within that range in the history. Culture also a time-requiring phenomenon, and since it is gradually formed and developed, it is entirely dependent on time and history. It was previously said that the historical perception of architecture is almost in conformity with the cultural perception of that, which shows the dependence and continuity of the concept of culture and history. The independent and public historical knowledge, even before the history of architecture is indicated is essential in the historical perception of architecture. The necessity of this knowledge is because what is occurred in the history, forming a phenomenon such as architecture is by no means one-dimensional and along with other affairs. In other words, architecture is like the other man-made constructions and its cultural manifestations are arisen from many actions and reactions of simultaneous, and even preceding and succeeding phenomena.

"Any human affair is dependent on the dimension of time, occurring within the history. What is making our modern architecture is undoubtedly the result of the gradual trend of an affair that is the consequence of the intellectual, social, political transformations as well as the intellectual, technical, and practical capability transformations in humans, during the history. Thus, dealing with architecture is necessarily requiring the recognition and the knowledge of historical 
backgrounds of architecture within the basis of social, intellectual, political, and governing evolutions of the area" (Gharibpour \& Toutounch, 2016).

\subsubsection{History of Political Transformations}

"Architecture at any time is affected by the political situations and the inclination and facilities of the governments in construction affairs. Moreover, the political ups and downs, as well as the transformations that occur during the courses of political history of a country are simultaneously affecting the constructions and architectural developments" (Nasr, 2007). Furthermore, the interactions between the governments as well as the history of wars, invasions, and other political interactions can be effective on the architectural transformations. The examples of these effects can be exploited for instance in the Seleucids era with their art and architecture in Iran, or in the Mongolian invasion with the transformations that occurred after that in the Iranian art and architecture affairs. Thus, paying attention to the existing connections between architecture and the dominating situations on the community at each era provides an appropriate basis for better perception of architecture in every land and country.

\subsubsection{History of Social and Cultural Transformations}

Similar to the political transformations, the cultural and social transformations have always affected the life, arts, and architecture, even providing the political or economic evolutions at the time of the social and cultural transformations. Emergence of intellectual and philosophical movements-artistic transformations of cultural interactions with other countries-intellectual revolutions, and similar phenomena, all can directly or indirectly, more or less, affect the architecture. "Architecture of each land is affected by the cultural and social transformations and intellectual movements due to them that occur in that land. Study of these transformations, both qualitatively and quantitatively, reveal the historical roots of the events in every historical period, ups and downs of the architectural condition, and the dominating intellectual movements. Similar to a human product, architecture also has close relations with the intellectual movements of a community, and their transformations and natures in that community" (Gharibpour \& Toutounch, 2016).

\subsubsection{History of Engineering and Technology}

As a profession that is established by arts, engineering, and technology, architecture has been affected by the developments of technological and engineering facilities, at each period and according to its occurring time and place. In fact, the eminence of architecture at each period and in any land has utmost dependence to the facilities that the development of science and technology has provided for the architects. It is clear that information about the history of engineering transformations in any land creates a clearer and more scientific basis for the knowledge of the history of architecture and the structural transformation trends, which is quite useful for the students of the history of architecture. 


\subsubsection{History of Art}

The other aspect in architecture is the artistic aspect of architecture. Since various arts and products have the required roles in the formation and evolution of architecture during the history, the profound and comprehensive perception of the history of architecture will not be possible without the knowledge about the common arts and products in any historical era. For example, looking at the Iranian architecture in the previous eras indicates role of arts, such as calligraphy, painting, marquetry, glazing, tiling, and mirror work, in the architectural developments and transformations.

\subsection{Geographic Domain}

As architecture is a time requiring affair and stuck to the history, it is also a place requiring affair, and hence, it has an inevitable continuity and dependence with the climate and geography of each land. "In its position, architecture is affected by the phenomena and factors that have their roots in geography. Geography of each land can be studied in three different categories, namely natural geography, human geography, and environmental geography" (Ditto). Thus, the effective subjects on architecture in the geographic domain can be defined accordingly.

\subsubsection{Climatic Conditions}

Considering the climatic conditions and compatible architecture with the climate is not a new subject in the architectural domain. Paying attention to the climatic conditions, especially in Iranian architecture, and creating the most appropriate type of architecture in coordination with the nature and the climate of each area is quite considerable. This subject is connected to identifying the geography of each area from one side, and engineering knowledge from the other side, and can be useful for the students of the history of architecture, from both of the aspects.

\subsubsection{The Elements and Natural Features of the Earth}

The past architecture, either in Iran or any other places in the world, has been formed by the elements, terrain, and natural features of the land base. In fact, the natural feature is one of the most important features for coordination of the past architecture, the nature, and it's forming basis. However, this attention has gradually been reduced, and interventions in the nature have been increased due to technological developments and also due to the changes in human attitudes.

\subsubsection{The Land Potential Resources}

"One of the branches in the geographical domain that is directly related to the architecture of an area includes the potential resources and capacities of that area. Identification and the knowledge of the available capacities, resources, and building materials of each region, their extractions, and their applications in architecture have great roles in creating the architecture in conformity with the geographical basis. Using the land potential resources or in other words, domes- 
tic materials has been considered as one of the architectural features of this country (Iran), since old ages, causing the reduction in costs, better responsiveness to the climatic problems, and achieving a compatible appearance with the environment in each area" (Ditto).

\subsubsection{Human Geography}

"Human geography analyzes the mutual relation of humans and the geographical factors. The effects of the environment left on human community and also the mutual effects that humans leave behind in their living environment due to their skills are studied in the human geography. Human geography considers the patterns and processes that form the interaction of human beings with different environments, which include human, political, cultural, social and economic aspects. While the main attention of the human geography is not to the physical prospect of the land, but the physical prospects that have extensive roles in human activities can hardly be ignored. Population geography, cultural geography (race and language), urban geography and planning, rural geography and planning, as well as regional geography and planning are among the subcategories of human geography, which are effective on architecture" (Ditto).

\section{Conclusion}

As a definite form of human constructions, architecture has various physical and apparent features, all of which are considered its identification parts that are not separate from it. However, the most principle aspect of architecture is its relation with the human life and the effects obtained from it. Accordingly, the appropriate definition about the history of architecture is one that considers the connection of architecture and human life. Since human life on earth is organized within the framework of different communities, it has obtained specific form in each area. This specific form of life in each land is called "culture". Thus, recognizing human life is indeed recognizing his bio-culture, everywhere in the world. As a phenomenon arisen from human life and for the human life, architecture is a cultural affair. Among the different approaches existing about the history of architecture, the approach towards the cultural history is the most appropriate definition of the history of architecture, due to its holistic approach and its attention towards architecture and the culture in life.

The most important result of this research is to help us know the architecture roots. The holistic nature of cultural history approach makes us consider all factors that may have contributed to the creation of architecture and leads to have a boarder and deeper understanding of the architectural phenomenon.

\section{Future Direction}

The present study shall be considered as a starting point for any research program in the future. In fact this study provides a deeper viewpoint into different architectural and related subjects. 


\section{References}

Allsopp, B. (1992). A Modern Theory of Architecture (pp. 50-120). Tehran: Sadra Press.

Bailer, R. (1999). Psychology Applied to Teaching (pp. 15-255). Tehran: University Publication Center Press.

Collingwood, R. (2006). The Idea of History (pp. 7-404). Tehran: Akhtaran Press. $\square$

Gardner, H. (1986). Art in the Passage of Time (pp. 50-400). Tehran: Negah Press.

Gharibpour, A., \& Toutounchi, M. (2016). Architecture Instruction with the Approach to Cultural History. Journal of Iran Architectural Studies, 10, 141-160.

Ghayoumi, B. M., \& Shahidi, N. (2013). Approach of Cultural History and Its Advantages and Possibilities in Iran Architectural Studies. Journal of Iran Architectural Studies, 15, 15-20.

Giedion, S. (1995). Space, Time, Architecture (pp. 40-230). Tehran: Scientific-Cultural Publication Co. Press.

Goleijani Moghadam, N. (2005). Historiology of Iranian Architecture: A New Approach with Regards to Deficiencies of Writing about History (pp. 10-150). Tehran: Tehran University Press.

Khoei, H. (2000). Critics and Pseudo-Critics. Ph.D. Thesis, Tehran: Tehran University.

Kostof, S. (1985). A History of Architecture: Setting and Rituals (pp. 103-255). London: Oxford Press.

Nasr, S. (2005). Human and Nature, the Spiritual Crisis of Modern Humans (pp. 120-218). Tehran: Islamic Culture Publication Center Press.

Nasr, S. (2007). Eternal Knowledge (pp. 25-80). Tehran: Mehr Newsha Press.

Stanford, M. (2003). An Introduction to the Philosophy of History (pp. 10-400). Tehran: Ney Press.

Warburton, N. (2016). Nature of Art (pp. 20-100). Tehran: Ney Press.

Zarrinkoub, A. (2009). History in Scale: Regarding History Writing (pp. 9-231). Tehran: Amir KabirPress.

Zevi, B. (1997). Architecture as Space: How to Look at Architecture (pp. 40-120). Tehran: Ketabe Emrouz Press. 